\title{
A STUDY OF R.C.C. BEAM-COLUMN CONNECTION SUBJECTED TO MONOTONIC LOADING
}

\author{
S. S. Patil ${ }^{1}$, S. S. Manekari ${ }^{2}$ \\ ${ }^{1,2}$ Department of Civil Engineering, Walchand Institute of Technology Seth Walchand Hirachand Marg, Ashok Chowk, \\ Solapur-413006 ( M.S.) India \\ sspatil1962@gmail.com,manekariss@rediffmail.com
}

\begin{abstract}
Beam and column where intersects is called as joint or Connection. The different types of joints are classified as corner joint, exterior joint, interior joint etc. on beam column joint applying quasi-static loading .i. e. monotonic loading on cantilever end of the beam and study of various parameters as to be find out on corner and exterior beam column joint i.e. maximum stress, minimum stress, displacement and variation in stiffness of beam column joint can be analyzed in Ansys software ( Non-Linear FEM Software) The various research studies focused on corner and exterior beam column joints and their behavior, support conditions of beam-column joints. Some recent experimental studies, however, addressed beam-column joints of substandard RC frames with weak columns, poor anchorage of longitudinal beam bars and insufficient transverse reinforcement. the behavior of exterior beam column joint is different than the corner beam column joint.
\end{abstract}

Keywords: beam, column, corner, exterior, joint, monotonic load, quasi-static, varying stiffness. $* * *$

\section{INTRODUCTION}

Earthquakes are one of the most feared natural phenomena that are relatively unexpected and whose impact is sudden due to the almost instantaneous destruction that a major earthquake can produce. Severity of ground shaking at a given location during an earthquake can be minor, moderate and strong which relatively speaking occur frequently, occasionally an rarely respectively. Design and construction of a building to resist the rare earthquake shaking that may come only once in 500 years or even once in 2000 years at a chosen project site even though life of the building itself may be only 50 to 100 years is too robust and also too expensive. Hence, the main intention is to make building earthquake-resistant that resist the effect of ground shaking although it may get damaged severely but would not collapse during even the strong earthquake. Thus, the safety of people and contents is assured in earthquake-resistant buildings. This is a major objective of seismic design codes throughout the world.

A Beam-Column Joints is defined as the portion of a column within the depth of the beams that frame into it. Formerly, the design of monolithic joints was limited to providing adequate encourage for the reinforcement. However the increasing use of high strength concrete, resulting in smaller member cross section, and the use large diameter of reinforcing bars now required that more attention be given to joint design and detailing.

\subsection{Exterior Joint Mechanism}

When the joint is applied with different loads the mechanism of force transfer takes place. This mechanism is shown in fig.1.
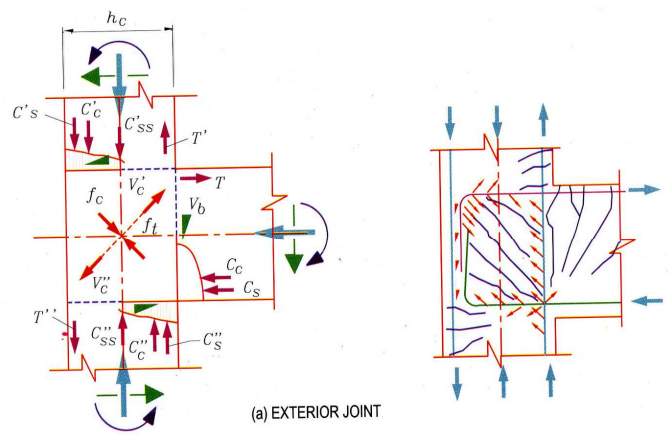

Fig1. Joint loads acting on the free body of a typical joint of a frame Subjected to gravity loads.(Exterior Seismic Beam Column Joint)

\section{LITERATURE REVIEW}

Vladmir Guilherne Haach, Ana Lucia Home De Cresce El Debs, Mounir Khalil El Debs

This paper investigates the influence of the column axial load on the joint shear strength through numerical simulations. The numerical study is performed through the software ABAQUS, 
based on Finite Element Method. A comparison of the numerical and experimental results is presented in order to validate the simulation. The results showed that the column axial load made the joint more stiff but also introduced stresses in the beam longitudinal reinforcement. A more uniform stress distribution in the joint region is obtained when the stirrup ratio is increased. Furthermore, some tension from the top beam longitudinal reinforcement is absorbed by the stirrups located at the upper part of the joint. This paper gives the affect of stirrup ratio to exterior beam-column joints where the beam is loaded monotonically. It was concluded that stirrups located in the upper region of the joint absorb part of the tension stress proceeding from beam longitudinal reinforcement and improve their anchorage.

Hegger Josef,Sherif Alaa and Roeser Wolfgang This paper investigate the behavior of exterior and interior beam-column joints by Nonlinear finite element analysis using ATENA a software for nonlinear analysis of reinforced concrete structures. The model has been calibrated using the results of the third author's tests. The behavior of exterior and interior beam-column turned out to be different. The parameters influencing the shear strength are not the same for both types of connections. Different parameters like effect of the material properties, effect of geometry of connection, effect of reinforcement, effect of concrete compressive strength and joint slenderness. The parameters influencing the shear capacity are different for exterior and interior connections.
The FE results were compared with the author's experimental results and the good agreement between the two was achieved.

\section{FRAMED JOINTS}

Beam column joints can be critical regions in reinforced concrete frames designed for inelastic response to severe seismic attack. As a consequence of seismic moments in columns of opposite signs immediately above and below the joint, the joint region is subjected to horizontal and vertical shear forces whose magnitude is typically many times higher than in the adjacent beams and columns.

Features of joint behavior: Under seismic action large shear forces may be introduced into beam-column joints irrespective of whether plastic hinges develop at column faces or at some other section of beams. These shear forces may cause a failure in the joint core due to the breakdown of shear or bond mechanisms or both.

Equilibrium criteria: As a joint is also a part of a column, examination of its function as a column component is instructive. An interior column extending between points of contra flexure, at half storey heights may be isolated as free body, as shown in fig. Actions introduced by symmetrically reinforced beams to the column are shown in fig. to be internal horizontal tension $\mathrm{T}_{\mathrm{b}}$ and compression $\mathrm{C}_{\mathrm{b}}$ forces and vertical beam shear $\mathrm{V}_{\mathrm{b}}$ forces.

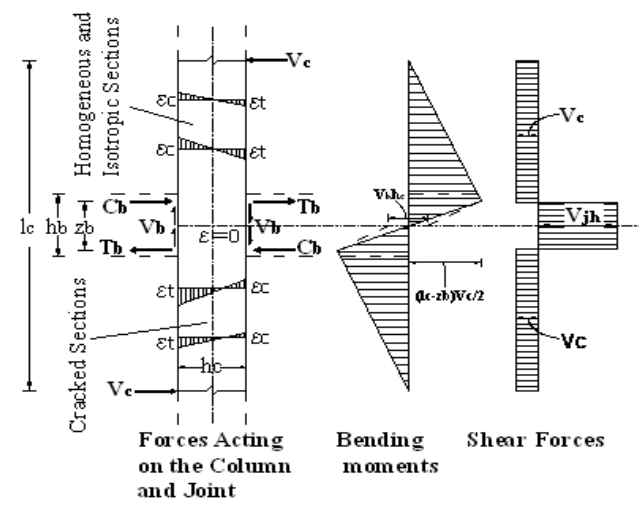

(a) (b) (c)

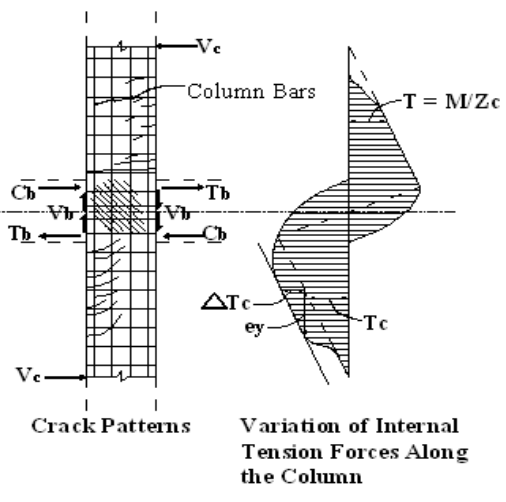

(d)

(e)

Fig.2. Features of column and joint behavior

Making approximation that $C_{b}=T_{b}$ and the beam shear on both sides of the joint are equal, equilibrium of the free body shown requires a horizontal column shear force of

$$
V_{c}=\frac{2 T_{b} Z_{b}+V_{b} h_{c}}{l_{c}}
$$

The intensity of the horizontal shear within the joint $V_{\mathrm{jh}}$ is typically four to six times larger than that across the column between adjacent joints $\mathrm{V}_{\mathrm{c}}$. 


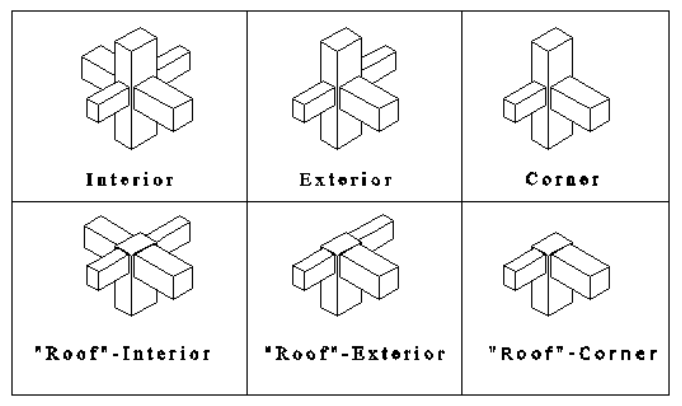

Fig3 Typical Beam Column Connections

\section{LOADING SYSTEMS}

\subsection{Types of Loading systems}

The behavior of building is studied with different types of loads.

1) Static loading

Static means slow loading in structural testing.

-Test of components

-Beams (bending), column (axial), beams and columns

Purpose of testing

-Determine strength limits

-Determine the flexibility/rigidity of structures

2) Quasi-static loading

Very slowly applied loading in one direction (monotonic)

3) Quasi-static reversed cyclic loading

Very slowly applied loading in both direction (cyclic)

4) Dynamic (random) loading

-Shake at the base or any other elevation of the structure

-Shaking similar to that during earthquakes.

\section{FINITE ELEMENT ANALYSIS}

The Finite Element Analysis is a numerical technique in which all complexities of the problems varying shape, boundary conditions and loads are maintained as they are but the solutions obtained are approximate. Solutions can be obtained for all problems by Finite Element Analysis.

Various steps involved in FEM are as follows.

1. Selection of field variables and the elements.

2. Discretization of structure.

3. Finding the element properties

4. Assembling element stiffness matrix

5. Solution of nodal unknowns

\section{ELEMENT TYPE USED}

Reinforced Concrete: An eight-node solid element, Solid65, was used to model the concrete. The solid element has eight nodes with three degrees of freedom at each node translations in the nodal $\mathrm{x}, \mathrm{y}$, and $\mathrm{z}$ directions. The element is capable of plastic deformation, cracking in three orthogonal directions, and crushing. The geometry and node locations for this element type are shown in below.

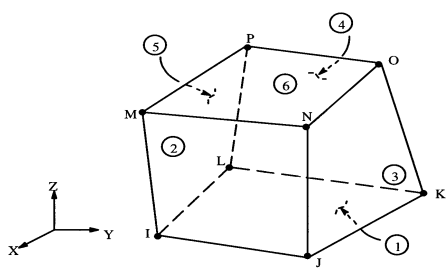

Fig4. Solid65 - 3-D reinforced concrete solid (ANSYS 1998)

A Link8 element is used to model the steel reinforcement. Two nodes are required for this element. Each node has three degrees of freedom, - translations in the nodal $\mathrm{x}, \mathrm{y}$, and $\mathrm{z}$ directions. The element is also capable of plastic deformation.

\section{MATERIAL PROPERTIES}

Concrete Development of a model for the behavior of concrete is a challenging task. Concrete is a quasi-brittle material and has different behavior in compression and tension. The tensile strength of concrete is typically $8-15 \%$ of the compressive strength (Shah, et al. 1995). Figure below shows a typical stress-strain curve for normal weight concrete (Bangash 1989).In compression, the stress-strain curve for concrete is linearly elastic up to about 30 percent of the maximum compressive strength. Above this point, the stress increases gradually up to the maximum compressive strength. After it reaches the maximum compressive strength $\sigma_{\text {cu }}$, the curve descends into a softening region, and eventually crushing failure occurs at an ultimate strain $\varepsilon_{\text {cu }}$. In tension, the stress-strain curve for concrete is approximately linearly elastic up to the maximum tensile strength. After this point, the concrete cracks and the strength decreases gradually to zero (Bangash 1989).

\subsection{Steel Reinforced Concrete [Smeared Model]}

\section{Material Properties}

In this project the structure has been modeled using Steel Reinforced Concrete. The material properties mentioned below act equivalent for a Smeared Reinforcement concrete model using solid 65 element in Ansys. Many research papers have been published using similar kind of model. Broujerdian et. al (2010) have worked using a similar approach. The used of this features enables obtaining good results with less solver and modeling time.

\section{PROBLEM STATEMENT}

\subsection{Problem Definition}

A ground plus five Storey RC office building is considered. Plan dimensions $: 12 \mathrm{~m} \times 12 \mathrm{~m}$ 
Location considered

Soil Type considered

: Zone-III

:Rock Soil

\subsection{General Data of Building:}

- Grade of concrete : $\quad$ M 20

- Grade of steel considered

- Live load on roof for earthquake)

- Live load on floors $\%$ for earthquake)

- Roof finish

- Floor finish

- $\quad$ Brick wall in longitudinal direction (BL) mm thick

- Brick wall in transverse direction (BT) : $150 \mathrm{~mm}$ thick

- Beam in longitudinal direction : $230 \times 300 \mathrm{~mm}$

- Beam in transverse direction : $\quad 230 \times 300 \mathrm{~mm}$

- Column size

- Density of concrete : $25 \mathrm{KN} / \mathrm{m}^{3}$

- Density of brick wall including plaster : $20 \mathrm{KN} / \mathrm{m}^{3}$

- Plinth beam(PB1) : $\quad 350 X 250 \mathrm{~mm}$

- Plinth beam(PB2) : $250 X 300 \mathrm{~mm}$

\subsection{Parametric Study}

The exterior and corner beam-column joints are studied with different parameters like i.e. Maximum principle stress, Minimum principle stress, Displacement, Deformation also studied end conditions of beam column joint i.e. fixed end conditions, Hinge end conditions and Stiffness variation of beam column joint i.e. Corner and Exterior joints.

\section{FINITE ELEMENT MODELLING AND}

\section{ANALYSISOF BEAM-COLUMN JOINTS}

The exterior and corner beam-column joint is considered to study joint behavior subjected to monotonic loading. Preparation of FE model is carried out based on results obtained from space frame analysis of a building located in zone-III. Model construction is done by defining geometrical joints and lines. Material definition is carried out prior to assigning of macro elements. The joint is fully restrained at the column ends. The load is applied at the tip of the beam in one direction.

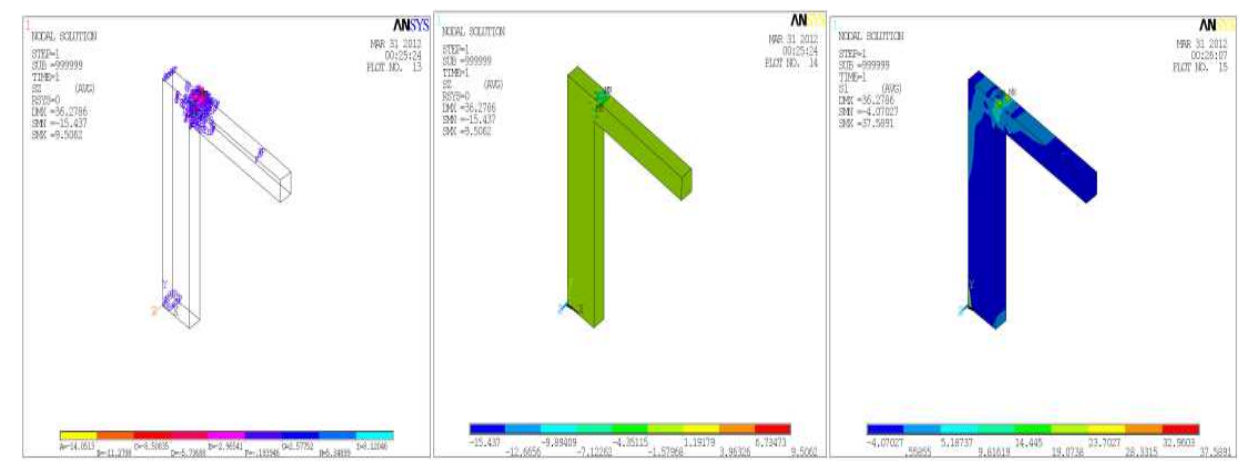

Fig5. Modeling of corner beam column joints in the Ansys

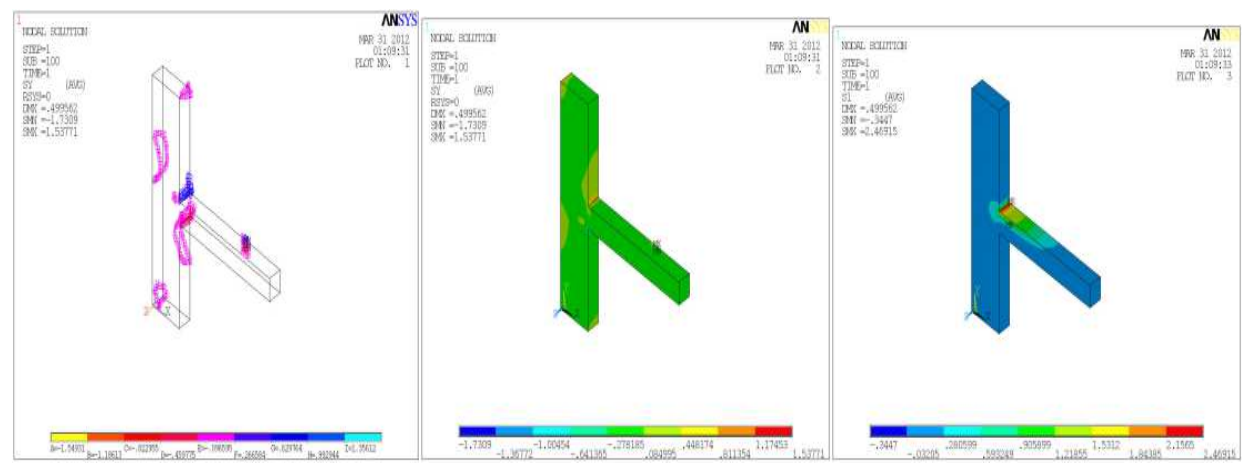

Fig.6..Modeling of Exterior beam column joints in the Ansys 


\section{RESULTS AND DISCUSSIONS}

9.1 Variation in stiffness of Corner beam column joint (For Displacement)

Table 1

\begin{tabular}{|c|c|c|c|c|}
\hline $\begin{array}{c}\text { Load } \\
\text { in } \\
\mathrm{KN}\end{array}$ & $\begin{array}{c}\text { Displa } \\
\text { cement } \\
\text { in } \mathrm{mm}\end{array}$ & $\begin{array}{c}\text { Displaceme } \\
\text { nt in } \mathrm{mm}\end{array}$ & $\begin{array}{c}\text { Displace } \\
\text { ment in } \\
\mathrm{mm}\end{array}$ & $\begin{array}{c}\text { Displacement } \\
\text { in } \mathrm{mm}\end{array}$ \\
\hline & $\begin{array}{c}\mathrm{Sj}=0.1 \\
8\end{array}$ & $\mathrm{Sj}=1.29$ & $\mathrm{Sj}=2.05$ & $\mathrm{Sj}=0.75$ \\
\hline 5 & 0.4172 & 0.34116 & 0.274849 & 0.5875 \\
\hline 10 & 0.8344 & 0.68233 & 0.549698 & 1.175 \\
\hline 15 & 1.6689 & 1.36467 & 1.099396 & 1.3512 \\
\hline 20 & 3.3478 & 2.7293 & 1.319256 & 1.6215 \\
\hline 25 & 3.6889 & 3.4095 & 1.649056 & 2.0268 \\
\hline 30 & 3.983 & 4.4295 & 2.141056 & 2.6346 \\
\hline
\end{tabular}

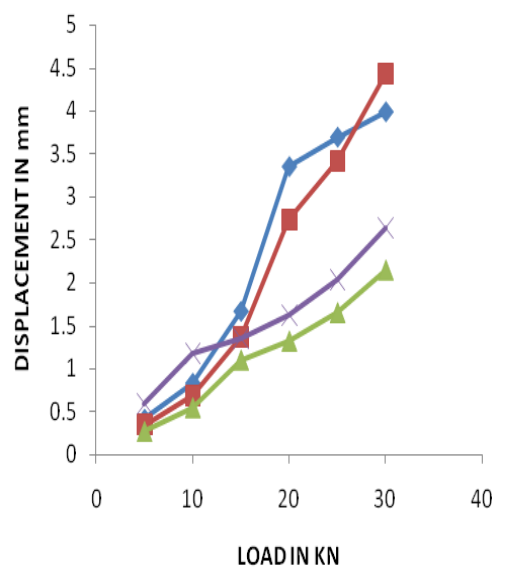

$\multimap$ Displacementin mm $\mathrm{Sj}=0.18$

-Displacementin mm $\mathrm{Sj}=1.29$

$\longleftarrow$ Displacementin $\mathrm{mm}$ $\mathrm{Sj}=2.05$

—Displacementin mm $\mathrm{Sj}=0.75$

Fig.7 LOAD VS MAXIMUM DEFORMATION

9.2 Variation in stiffness of corner beam column joint (Minimum Stress)

Table 2

\begin{tabular}{|l|l|l|l|l|}
\hline $\begin{array}{l}\text { Load } \\
\text { in KN }\end{array}$ & $\begin{array}{l}\text { Mini. Stress } \\
\text { in N/mm2 }\end{array}$ & $\begin{array}{l}\text { Mini. } \\
\text { Stress in } \\
\mathrm{N} / \mathrm{mm} 2\end{array}$ & $\begin{array}{l}\text { Mini. } \\
\text { Stress } \\
\mathrm{In} \mathrm{N} / \mathrm{mm} 2\end{array}$ & $\begin{array}{l}\text { Mini. } \\
\text { Stress } \\
\mathrm{In} \mathrm{N} / \mathrm{mm} 2\end{array}$ \\
\hline & $\mathrm{Sj}=0.18$ & $\mathrm{Sj}=1.29$ & $\mathrm{Sj}=2.05$ & $\mathrm{Sj}=0.75$ \\
\hline 5 & -0.931495 & -0.889535 & -0.922823 & -0.035402 \\
\hline 10 & -3.92411 & -1.21114 & -1.33809 & -0.88506 \\
\hline 15 & -4.00092 & -2.12256 & -1.53242 & -1.77012 \\
\hline 20 & -6.00393 & -2.13257 & -1.56506 & -2.27215 \\
\hline 25 & -6.94422 & -2.33399 & -1.66497 & -2.30116 \\
\hline 30 & -7.60862 & -2.34361 & -1.8868 & -3.2847 \\
\hline
\end{tabular}

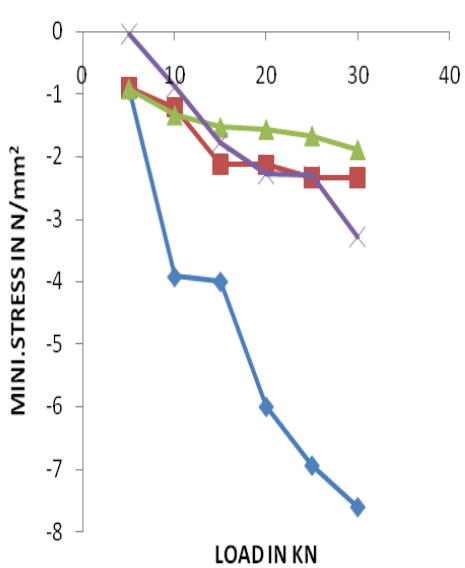

$\leadsto$ Mini.Stress in N/mm2 $\mathrm{Sj}=0.18$

-Mini.Stress in N/mm2 $\mathrm{Sj}=1.29$

- Mini.Stress in N/mm2 $\mathrm{Sj}=2.05$

$\leftarrow$ Mini.Stress in N/mm2 $\mathrm{Sj}=0.75$

Fig.8.LOAD VS MINIMUM STRESS

\subsection{Variation in stiffness of corner beam column joint} (Maximum Stress)

Table 3

\begin{tabular}{|c|c|c|c|c|}
\hline $\begin{array}{l}\text { Load } \\
\text { in KN }\end{array}$ & $\begin{array}{l}\text { Maxi. } \\
\text { Stress } \\
\text { in N/mm2 }\end{array}$ & $\begin{array}{l}\text { Maxi. } \\
\text { Stress } \\
\text { in N/mm2 }\end{array}$ & $\begin{array}{l}\text { Maxi. } \\
\text { Stress } \\
\text { in } \\
\mathrm{N} / \mathrm{mm} 2\end{array}$ & $\begin{array}{l}\text { Maxi. } \\
\text { Stress in } \\
\mathrm{N} / \mathrm{mm} 2\end{array}$ \\
\hline & $\mathrm{Sj}=0.18$ & $\mathrm{Sj}=1.29$ & $\mathrm{Sj}=2.05$ & $\mathrm{Sj}=0.75$ \\
\hline 5 & 0.303477 & 0.3956 & 0.389974 & 0.008042 \\
\hline 10 & 2.20581 & 1.66923 & 0.585308 & 0.201056 \\
\hline 15 & 2.22582 & 1.67924 & 1.15246 & 0.402113 \\
\hline 20 & 3.77446 & 1.96634 & 1.20463 & 1.21377 \\
\hline 25 & 4.6321 & 2.93769 & 1.29138 & 1.23761 \\
\hline 30 & 6.17119 & 6.50058 & 2.3821 & 4.01801 \\
\hline
\end{tabular}

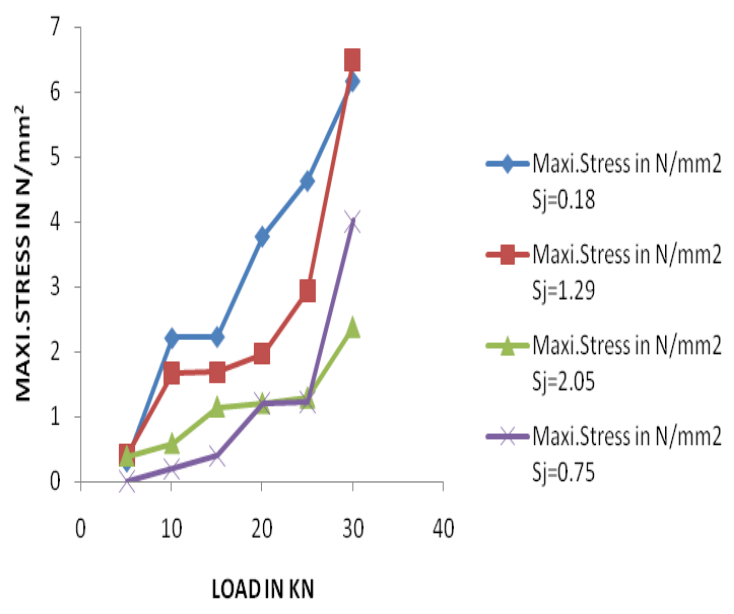

Fig.9. LOAD VS MAXIMUM STRESS GRAPH 


\subsection{Variation in stiffness of Exterior beam column} joint (For Displacement)

\section{Table 4}

\begin{tabular}{|l|l|l|l|l|}
\hline $\begin{array}{l}\text { Loa } \\
\mathrm{d} \text { in } \\
\mathrm{KN}\end{array}$ & $\begin{array}{l}\text { Displaceme } \\
\mathrm{nt} \text { in } \mathrm{mm}\end{array}$ & $\begin{array}{l}\text { Displaceme } \\
\text { nt in } \mathrm{mm}\end{array}$ & $\begin{array}{l}\text { Displacem } \\
\text { ent in } \mathrm{mm}\end{array}$ & $\begin{array}{l}\text { Displace } \\
\text { ment in } \\
\mathrm{mm}\end{array}$ \\
\hline & $\mathrm{Sj}=1.29$ & $\mathrm{Sj}=2.05$ & $\mathrm{Sj}=0.75$ & $\mathrm{Sj}=0.18$ \\
\hline 5 & 0.604115 & 0.60052 & 0.213883 & 0.507809 \\
\hline 10 & 1.20823 & 1.20104 & 0.427767 & 1.0156 \\
\hline 15 & 2.41646 & 1.38119 & 0.641712 & 1.16794 \\
\hline 20 & 2.8996 & 1.6571 & 1.81128 & 1.40134 \\
\hline 25 & 3.6244 & 2.0714 & 2.12017 & 1.75134 \\
\hline 30 & 3.9248 & 2.6927 & 2.60442 & 2.27664 \\
\hline
\end{tabular}

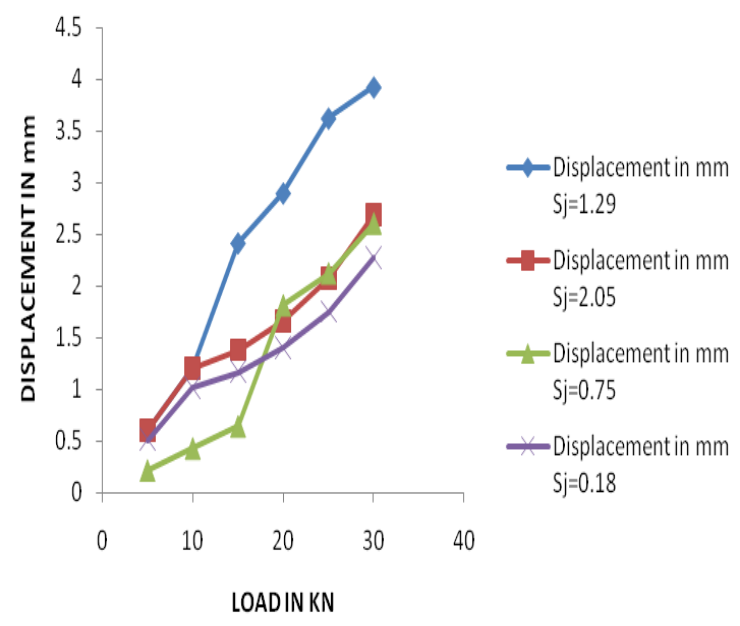

Fig.10. LOAD VS MAXIMUM DEFORMATION

\subsection{Variation in stiffness of Exterior beam column}

\section{joint (Minimum Stress)}

Table 5

\begin{tabular}{|l|l|l|l|l|}
\hline $\begin{array}{l}\text { Load } \\
\text { in } \\
\mathrm{KN}\end{array}$ & $\begin{array}{l}\text { Mini. } \\
\text { Stress in } \\
\mathrm{N} / \mathrm{mm} 2\end{array}$ & $\begin{array}{l}\text { Mini. } \\
\text { Stress in } \\
\mathrm{N} / \mathrm{mm} 2\end{array}$ & $\begin{array}{l}\text { Mini. } \\
\text { Stress in } \\
\mathrm{N} / \mathrm{mm} 2\end{array}$ & $\begin{array}{l}\text { Mini. } \\
\text { Stress in } \\
\mathrm{N} / \mathrm{mm} 2\end{array}$ \\
\hline & $\mathrm{Sj}=1.29$ & $\mathrm{Sj}=2.05$ & $\mathrm{Sj}=0.75$ & $\mathrm{Sj}=0.18$ \\
\hline 5 & -0.858169 & -2.09364 & -0.429264 & -0.88953 \\
\hline 10 & -1.71634 & -3.06832 & -0.858527 & -2.25308 \\
\hline 15 & -2.33399 & -4.05034 & -1.397001 & -2.68991 \\
\hline 20 & -2.60959 & -4.899265 & -1.57095 & -2.88285 \\
\hline 25 & -2.97925 & -5.79853 & -2.13031 & -3.91109 \\
\hline 30 & -5.54457 & -6.09465 & -2.83467 & -4.5792 \\
\hline
\end{tabular}

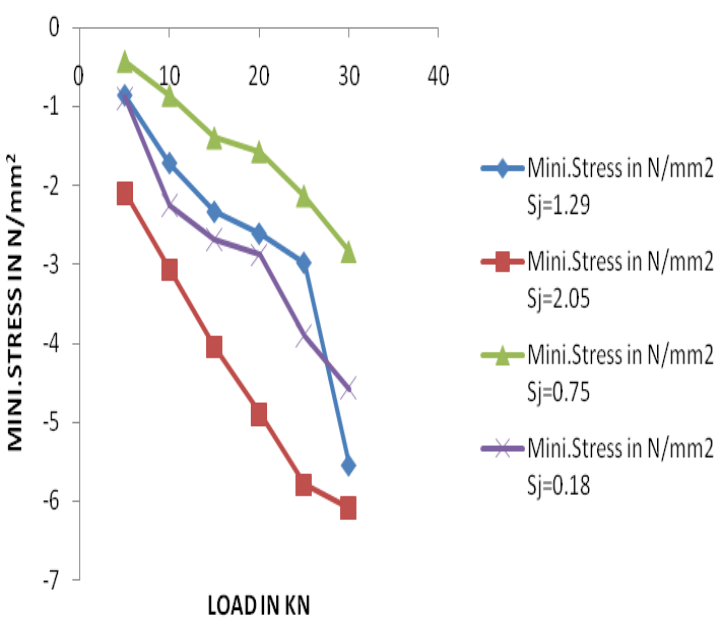

Fig.11. LOAD VS MINIMUM STRESS GRAPH

9.6 Variation in stiffness of Exterior beam column joint (Maximum Stress)

\section{Table6}

\begin{tabular}{|l|l|l|l|l|}
\hline Load & Maxi. & Maxi. & $\begin{array}{l}\text { Maxi. } \\
\text { Stress }\end{array}$ & $\begin{array}{l}\text { Maxi. } \\
\text { Stress } \\
\text { in }\end{array}$ \\
\hline & $\begin{array}{l}\text { Stress in } \\
\mathrm{N} / \mathrm{mm} 2\end{array}$ & $\begin{array}{l}\text { Stress in } \\
\text { in } / \mathrm{mm} 2\end{array}$ & $\mathrm{~N} / \mathrm{mm} 2$ & $\mathrm{~N} / \mathrm{mm} 2$ \\
\hline & $\mathrm{Sj}=1.29$ & $\mathrm{Sj}=2.05$ & $\mathrm{Sj}=0.75$ & $\mathrm{Sj}=0.18$ \\
\hline 5 & 1.5166 & 0.67842 & 1.3244 & 2.18446 \\
\hline 10 & 3.0332 & 3.00113 & 2.64879 & 3.8436 \\
\hline 15 & 4.543 & 3.2643 & 3.55204 & 4.4024 \\
\hline 20 & 6.5429 & 3.50445 & 7.08526 & 6.82696 \\
\hline 25 & 8.0439 & 4.00889 & 8.40464 & 7.9676 \\
\hline 30 & 10.0439 & 4.678425 & 9.2199 & 9.9624 \\
\hline
\end{tabular}

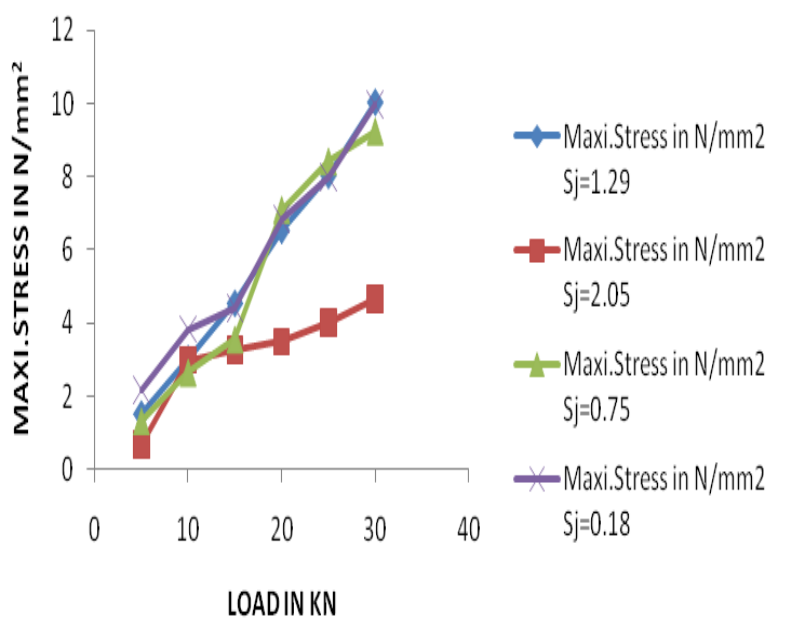

Fig12. LOAD VS MAXIMUM STRESS GRAPH 


\section{CONCLUSIONS}

1) As load increases displacement, minimum stress and maximum stress also increases.

2) For stiffness variation of corner joint for $\mathrm{Sj}=0.18$ the displacement is minimum as compare to $\mathrm{Sj}=1.29$, $\mathrm{Sj}=2.05, \mathrm{Sj}=0.75$.

3) For stiffness variation of corner joint for $\mathrm{Sj}=0.18$ the minimum stress is more as compare to $\mathrm{Sj}=1.29$ and $\mathrm{Sj}=2.05$, for $\mathrm{Sj}=0.75$ the minimum stress is maximum as compare to $\mathrm{Sj}=0.18$.

4) For stiffness variation of corner joint for $\mathrm{Sj}=0.18$ the maximum stress is more as compare to $\mathrm{Sj}=1.29$ and $\mathrm{Sj}=2.05$, for $\mathrm{Sj}=0.75$ the maximum stress is maximum as compare to $\mathrm{Sj}=0.18$.

5) For stiffness variation of Exterior joint for $\mathrm{Sj}=1.29$ the displacement is minimum as compare to $\mathrm{Sj}=2.05$, for $\mathrm{Sj}=0.75$ and for $\mathrm{Sj}=0.18$ the displacement is maximum as compare to $\mathrm{Sj}=1.29$.

6) For stiffness variation of Exterior joint for $\mathrm{Sj}=1.29$ the minimum stress is more as compare to $\mathrm{Sj}=2.05$ and $\mathrm{Sj}=0.75$, for $\mathrm{Sj}=0.18$ the minimum stress is more as compare to $\mathrm{Sj}=1.29$.

7) For stiffness variation of Exterior joint for $S j=1.29$ the maximum stress is less as compare to $\mathrm{Sj}=2.05$.for remaining stiffness $\mathrm{Sj}=0.75$ and $\mathrm{Sj}=0.18$ the maximum stress is less. ( minimum )

8) As stiffness of the structure changes the displacement, minimum stress and maximum stress changes Nonlinearly.

9) The behavior of corner beam column joint is different than that of the exterior beam column joint.

Where $\mathbf{S j}=$ Joint Stiffness factor i.e. Stiffness of Beam / Stiffness of Column Ratio

\section{REFERENCES}

[1]. Murty.C.V.R, Rai.C.Durgesh, Bajpai.K.K and Jain.S.K (April 2001) "Anchorage detail and joint design in seismic RC Frames."The Indian Concrete Journal pp 274-280.

[2]. Pampanin.S., Calvi.G.M. and Morati.M.(1998) "Seismic Behavior of Reinforced Concrete Beam-Column Joints designed for Gravity Loads" 12th European Conference on Earthquake Engineering pp 1-10.

[3]. R. Vollum* and D. Parker (2008) "External beam-column joints design to Eurocode2" Magazine of Concrete Research pp 511-521.

[4]. Shamim Mohammad and Kumar. V (1999) "Behavior of reinforced concrete Beam column joints-A review "Journal of Structural Engineering Vol.26, No.3, Pp.207-214.

[5]. Shin.S.W., Lee.S.K. AND Ghosh.S.K.(1992) "High Strength concrete beam-Column joints" Proceedings of the Tenth World Conference on Earthquake Engineering pp 31453149.

[6]. Uma. S. R and Meher Prasad. A "Seismic Behavior of Beam Column Joints in Reinforced Concrete Moment Resisting Frames”Document No.: IITK-GSDMA-EQ31-V1.0,
Final Report: A - Earthquake Codes, IITK-GSDMA Project on Building Codes.

[7]. Vladimir Guilherma Haach, Ana Lucia Home De Cresce El Debs and Mounir Khalil El Debs (2008) "Evaluation of the influence of the column axial load on the behavior of monotonically loaded R/C exterior beam-column joints through Numerical simulations "Engineering Structures pp 965-975.

\section{BIOGRAPHIES:}

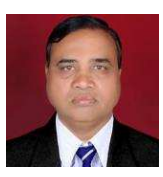

Prof. Patil S.S, B.E. (Civil), M.E. (Civil Structures) , $\mathrm{PhD} * *$

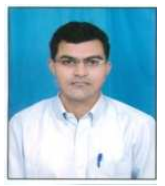

Mr. Manekari S.S.B.E. (Civil), M.E. (Civil Structures),L.M.( ISSE) 